\title{
MODULATORY ROLE OF MELATONIN ON THE STRUCTURE OF HARD PALATAL MUCOSA OF AGED RATS
}

\author{
Rania Ahmed Awwad*
}

\begin{abstract}
Introduction: Aging greatly diminishes the ability of oral tissues to withstand various types of functional insults, and reduces cell regeneration. Hence, anti-oxidation is mandatory to preserve oral tissues especially while aging. Melatonin is an anti-oxidant with established potential in hindering age-related changes. Aim: to evaluate the extent of anti-oxidant and anti-inflammatory potentials of melatonin on aged hard palatal tissues of rats.
\end{abstract}

Materials and Methods: twenty-one Albino rats 200-250 gms each, were used in this study. They were equally divided into 3 groups; Control Young Gp: 6 months of age, Control Senile Gp:18 months of age, and Melatonin Gp: 18 months of age. After 8 weeks, rats were sacrificed by high dose of anesthesia. The hard-palatal mucosae of all rats were separated and processed for histologic examination by H\&E, Masson Trichrome stain, and immuno-histochemical staining by Anti-PCNA, then examined by light microscopy.

Results: the control senile Gp showed statistically significant increase in vacuolated epithelial cells and area percentage of mature collagen fibers, as well as statistically significant reduction in PCNA-positive cells and apparent reduction of epithelial thickness. On the other hand, the melatonin Gp displayed statistically significant increase in PCNA-positive cells, area percentage of immature collagen fibers, while significant decrease in No. of vacuolated epithelial cells and apparent increase of epithelial thickness.

Discussion: Aging resulted in deteriorated regeneration, enhanced apoptosis, with reduced cellularity and vascularity. On the other hand, melatonin greatly improved cellular proliferation, reduced apoptosis, enhanced CT tissue regeneration and collagen production. As well as reduction in inflammatory cells.

KEY WORDS: Aging, Hard Palatal Mucosa, Melatonin.

\footnotetext{
* Lecturer of Oral biology, Faculty of Dentistry, Ain Shams University.
} 


\section{INTRODUCTION}

The oral cavity is responsible for many complex functions, such as food processing, deglutition, taste and speech. These functions require certain structural features in different oral regions and are regulated by chemosensory and somatosensory neurons, converging in the oral cavity to transmit various stimuli ${ }^{[1]}$.

Aging, reduces the ability to detect the mechanical properties of food material. Moreover, it is well established that xerostomia is greatly associated with aging, as well as reduced taste perception ${ }^{[2]}$. Declined mechano-sensitivity and chemo-sensitivity greatly affect the quality of life, predisposing to aging-related oral lesions.

Histologically, reduction in overall innervation density to human gingiva have been demonstrated with aging. Similarly, in the aging murine hard palate, reductions in complexity and size of Meissner's corpuscles have been reported. The lining of the oral cavity provides protection from the forces of mastication and other potentially noxious effects. Therefore, aging involves many changes occurring within the oral mucosa ${ }^{[3]}$.

Antioxidants are molecules that can reduce or even prevent free radicals and other reactive oxygen species (ROS) generation. ROS are known to cause tissue damage via several mechanisms, such as activation of Matrix-Metalloproteinases (MMPs) leading to tissue-collagen destruction and enhanced apoptosis of various cells within the tissue [4]. Thus, anti-oxidation is now a highly recommended mode of intervention to manage variety of chronic diseases as well as slowing down the effects of aging on tissues ${ }^{[5]}$. Melatonin is a potent antioxidant with proven anti-inflammatory functions. Numerous in vitro and in vivo studies have documented the ability of melatonin to protect against free radical-induced tissue damage ${ }^{[6-8]}$. Hence, this study presents a histological and immuno-histochemical evaluation of the modulatory effect of melatonin on various structural elements of the hard-palatal mucosa in aged rats in comparison with young adult rats.

\section{MATERIALS AND METHODS}

\section{Animals}

This research was reviewed and approved by the research ethics committee of faculty of dentistry, Ain Shams University (Approval number: FDASU REC IR).

In this study, twenty-one adult male Albino rats weighing between 200-250 grams were used. The rats were housed in separate cages, seven rats per cage, in the Animal House of the Medical Research Center of Ain Shams University.

They were maintained under controlled conditions of temperature $\left(25 \pm 2{ }^{\circ} \mathrm{C}\right)$, humidity $(50 \pm 5 \%)$, and light (14 and $10 \mathrm{~h}$ of light and dark, resp.). The animals were provided with food and water ad libitum. Animals were under constant supervision of specialized veterinarian throughout the whole experiment.

\section{Materials}

Melatonin in the form of rapid release capsules (10mg) was purchased from Puritan's Pride NY, USA.

\section{Study Design:}

Rats were divided into three groups, seven rats each, as follows:

1. Group I: In which seven rats (six months old, equivalent to eighteen years in humans) ${ }^{[9]}$. They were kept in a normal, healthy state throughout the experiment, for eight consecutive weeks and fed ad libitum.

2. Group II: This group consisted of fourteen rats aged 18 months (equivalent to 45 years in humans) [9], and was equally subdivided into 2 subgroups seven rats each as follows: 
Subgroup II.a: Animals in this subgroup served as a positive control (senile control) for other groups.

Subgroup II.b: Animals in this subgroup received Melatonin via gastric gavage at a dose of $10 \mathrm{mg} / \mathrm{kg} /$ day dissolved in $1 \mathrm{ml}$ of distilled water, for eight consecutive weeks ${ }^{[7]}$.

\section{Sample preparation}

After eight weeks, rats of all groups were sacrificed by a high dose of anesthesia at the end of the experiment, the palatal mucosa was separated and fixed immediately in $10 \%$ phosphate buffered formaldehyde solution for 48 hours. The specimens were properly washed under running water then dehydrated by transferring them through increasing concentrations of alcohol. Then, specimens were transferred to xylene to be cleared from alcohol then infiltrated in paraffin and embedded in the paraffin wax blocks. $4 \mu \mathrm{m}$-thick sections were put in xylene and transferred in descending concentrations of alcohol then distilled water for removal of paraffin wax ${ }^{[10]}$. The sections were finally stained by Hematoxylin \& Eosin (H\&E), Masson Trichrome special stain (for collagen demonstration) and AntiProliferating Cell Nuclear Antigen (Anti-PCNA) to evaluate regeneration capacity of the tissue.

\section{Masson Trichrome Staining Technique}

This method was used to detect collagen fibers within tissues, on formalin-fixed, paraffinembedded sections. Collagen fibers will be stained blue and the nuclei will be stained black and the background is stained red. Immature collagen fibers will display distinct blue coloration, while mature fibers will appear reddish blue or even red.

\section{Procedure}

1. Sections were deparaffinized and rehydrated through 100\% alcohol, 95\% alcohol 70\% alcohol.

2. Section were then washed in distilled water.
3. They were re-fixed in Bouin's solution for 1 hour at $56 \mathrm{C}$ to improve staining quality.

4. Sections were washed under running tap water for 5-10 minutes to eliminate yellow coloration.

5. They were stained in Weigert's iron hematoxylin working solution for 10 minutes.

6. Then, they were rinsed in running warm tap water for 10 minutes.

7. Sections were washed in distilled water.

8. They were stained in Biebrich Scarlet-Acid Fuchsin solution for 10-15 minutes.

9. Then, washed in distilled water

10. They were differentiated in PhosphomolybdicPhosphotungstic acid solution for 10-15 minutes.

11. Section were then transferred directly (without rinse) to Aniline Blue solution and stain for 5-10 minutes. They were then rinsed briefly in distilled water and differentiated in $1 \%$ acetic acid solution for 2-5 minutes.

12. They were washed in distilled water.

13. Then, dehydrated very quickly through $95 \%$ ethyl alcohol, absolute ethyl alcohol to wipe off Biebrich Scarlet-Acid Fuchsin staining and then, cleared in xylene.

14. Section were finally mounted with resinous mounting medium ${ }^{[10]}$.

\section{Immunohistochemical staining using Anti-PCNA}

Over electrically charged slides, $4 \mu \mathrm{m}$ sections were mounted and fixed in $65^{\circ} \mathrm{C}$ oven for an hour. The sections were deparaffinized and rehydrated, washed and immersed in Tris buffered solution (20 mM Tris- $\mathrm{HCl}, 150 \mathrm{mM} \mathrm{NaCl}, \mathrm{pH}$ 7.4) for $\mathrm{pH}$ adjustment. The activity of endogenous peroxidase was inhibited by sections incubation in $0.3 \%$ hydrogen peroxide $\left(\mathrm{H}_{2} \mathrm{O}_{2}\right)$ at room temperature for $30 \mathrm{~min}$. Slides were placed in $(100 \mu \mathrm{l})$ blocking solution (normal goat serum) at room temperature 
for $30 \mathrm{~min}$ to facilitate antigen retrieval and reduce non-specific background staining, and then incubated with primary anti-body (mouse monoclonal Anti-PCNA antibody, Clone PC10) at room temperature for $60 \mathrm{~min}$. The sections were washed by PBS (0.1 M phosphate, $0.15 \mathrm{M} \mathrm{NaCl}$; $\mathrm{pH}$ 7.5) and incubated with secondary biotinylated antibody (Biotinylated horse anti-mouse $\mathrm{IgG}$ ) at room temperature in a humidified chamber for an hour, then incubated with avidin-biotin horseradish peroxidase complex for $30 \mathrm{~min}$. The color reaction was developed when adding DAB solution (0.5 $\mathrm{mg} / \mathrm{ml} \mathrm{DAB}$ and $0.1 \% \mathrm{H} 2 \mathrm{O} 2$ ) to the sections for $10 \mathrm{~min}$, after that, washed with distilled water. The sections were counterstained by hematoxylin for 2 min, dehydrated in graded alcohol and cleared by xylene. Finally, cover slips were put in place and the sections were examined under LM ${ }^{[11]}$.

\section{Histo-morphometric Analysis:}

Images of Anti-PCNA immune-stained sections, and H\&E-stained sections were analyzed by Image J software (Version 1.41a, NIH, USA) for histo-morphometric analysis, in the Precision Measurement Unit, Oral Pathology Department, Faculty of Dentistry, Ain Shams University, to count the number of immune-positive cells per unit area in the epithelium of the studied specimens. Also, the same software was used to count the number of vacuolated epithelial cells in $\mathrm{H} \& \mathrm{E}$ stained sections as well as the epithelial thickness among tested groups. Area percentage of collagen fibers in Masson Trichrome stained sections was also estimated. Three representative specimens were chosen from each group. Three representative fields were assessed/specimen to display the whole epithelium, considerable area from the underlying C.T, as well as proper Anti-PCNA reaction. The area of each examined field was $0.79 \mathrm{~mm}^{2}$ at $20 \mathrm{x}$ objective magnification. Fields were captured by a digital camera (Canon DSLR EOS 1200D, Japan) which was mounted on a light microscope (BX60, Olympus, Japan). The obtained images were transferred to the computer system for analysis.

\section{Statistical analysis}

Numerical data of mean number of Anti-PCNA positive cells, mean number of vacuolated epithelial cells, and area percentage for collagen fibers, and epithelial thicknesses among tested groups, were examined for normality by monitoring the distribution of data and using tests of normality. One-way ANOVA test was performed to compare between the groups. When ANOVA test was significant, Bonferroni's post-hoc test was done for pair-wise comparisons between each two groups. The significance level was set at $\mathrm{P} \leq 0.05$. Statistical analysis was performed using IBM ${ }^{\circledR} \quad$ SPSS ${ }^{\circledR}$ Statistics Version 20 for Windows.

\section{RESULTS}

\section{Histological Results}

\section{Hematoxylin \& Eosin $(H \& E)$}

\section{a) Group I (Young Control)}

Examination of H\&E stained sections of the palatal mucosa of this group showed normal appearance of thick ortho-keratinized stratified squamous epithelium, covered by well-developed keratin layer. Intraepithelial cell vacuolations were rarely spotted. The underlying connective tissue showed normal histological features. Spindleshaped fibroblasts with basophilic cytoplasm were regularly arranged \& intermingled with well-formed collagen fibers. Very few inflammatory cells were detected close to blood vessels (Fig.1).

\section{b) Group II (Senile Rats)}

\section{Subgroup II.a. (Senile Control)}

In this group, the epithelial layer was of uneven thickness and showed a detached, thin and discontinuous keratin layer. Many epithelial cells revealed intracytoplasmic cell-vacuolations. The underlying connective tissue showed occasional inflammatory cell infiltration, few blood vessels of narrow lumina and extracellular edema. Some areas showed hyalinization of collagen fibers (Figure 2a,b). 


\section{Subgroup II.b. (Melatonin Gp)}

Examination of H\&E stained sections of the palatal mucosa of this group showed almost normal appearance of ortho-keratinized stratified squamous epithelium, covered by keratin layer. Intraepithelial cell vacuolations were markedly reduced or even rarely detected. The underlying connective tissue showed normal histological features. Very few inflammatory cells were observed (Figure 3 ).

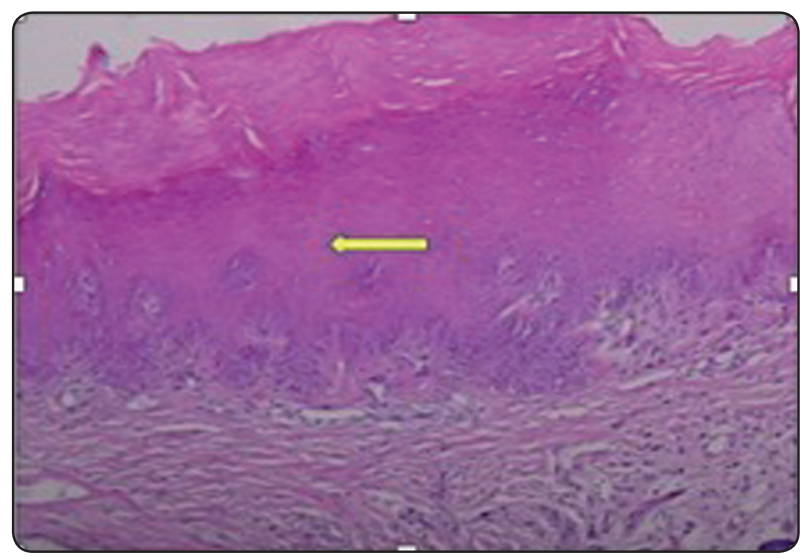

Fig. (1): A photomicrograph of group I showing normal palatal mucosa with thick epithelium and keratin, few intracytoplasmic vacuolations of epithelial cells(arrow), well-formed, thick, even keratin layer, CT with welldeveloped collagen fibers \& blood vessels. (H\&E, Orig Mg. x 200).

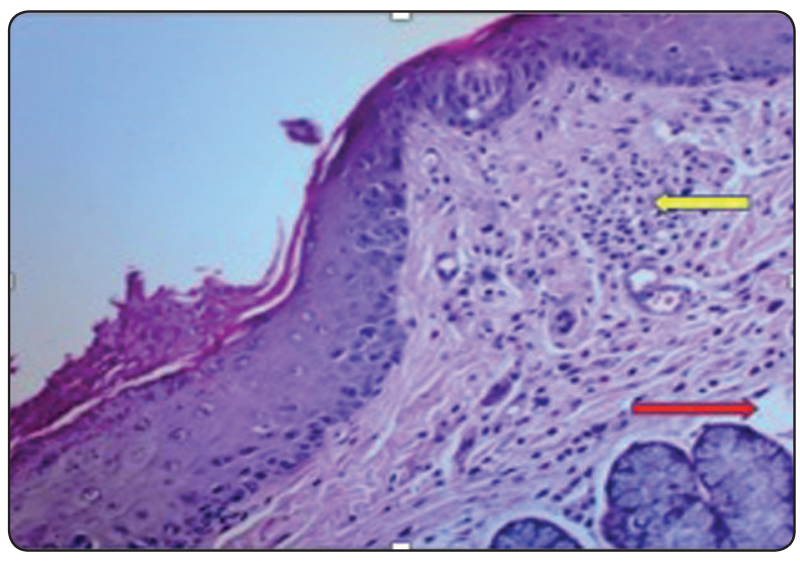

Fig. (2 b): A photomicrograph of hard palatal mucosa of subgroup IIa showing keratin layer of uneven thickness, areas of inflammatory cell infiltration (yellow arrow), extracellular edema (red arrow) (H\&E, Orig. Mg. x 200).

\section{Masson Trichrome Staining Results}

\section{a) Group I (Young Control)}

Light microscopic (LM) examination of specimens stained with Masson Trichrome special stain revealed normal-looking epithelium with thick, even keratin layer. C.T displayed intermingling of mature (red-colored) and immature (blue-colored) collagen fibers. Blood vessels showed normal structure and no extracellular edema was detected, Figure (4).

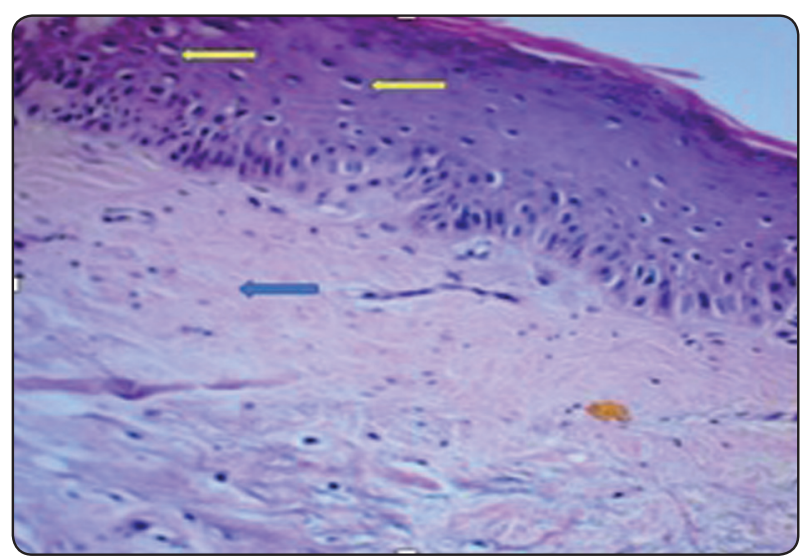

Fig. (2a): A photomicrograph of hard palatal mucosa of subgroup IIa showing epithelium with numerous intracytoplasmic vacuolations (yellow arrows), reduced epithelial thickness, CT showed areas of hyalinization (blue arrow) and few narrow blood vessels (H\&E Orig. $\operatorname{Mg}$ x 400).

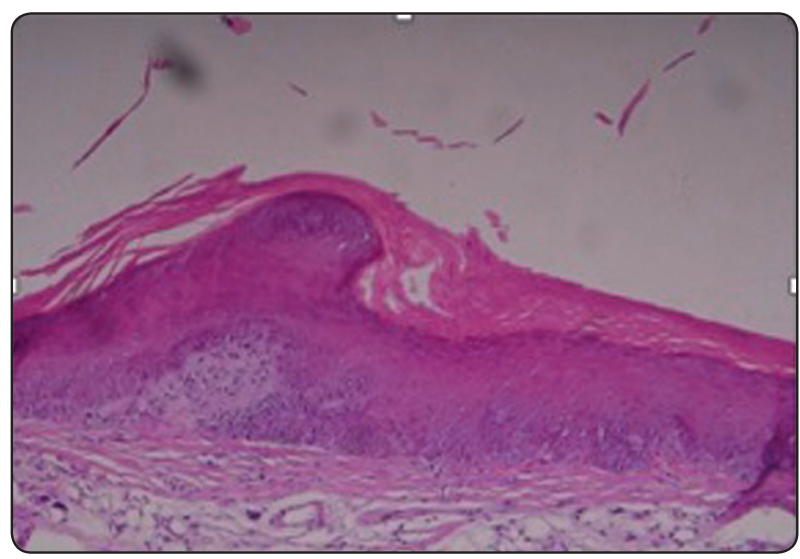

Fig. (3) A photomicrograph of hard palatal mucosa of subgroup II.b, showing rarely detected intra-epithelial cell vacuolations, well-formed keratin layer, rare presence of inflammatory cells in CT (H\&E, Orig. Mg. x 200). 


\section{b) Group II (Senile Rats)}

\section{Sub-group II.a (Senile Control)}

LM examination of this group showed epithelium with many cytoplasmic vacuolations. C.T presented abundant, thick, mature (reddish) collagen fibers with some areas of extracellular edema. Blood vessels were very few and with narrow lumen, Fig (5).

\section{Sub-group II.b (Melatonin)}

This group's specimens revealed normal-looking epithelium. CT with numerous, normal-looking blood vessels of various diameters. No extracellular edema was seen. Most of collagen fibers were intensely stained blue (immature), Figure (6).

\section{Immunohistochemical Staining (using anti-PC-} NA) Results

Anti-PCNA stain was used to detect the proliferating cells as the positive reactions revealed brown nuclear staining.

\section{a) Group I (Young Control)}

LM examination of this groups' specimens showed distinct positive reaction in all basal and few para-basal cells of the epithelium, some cells with positive reaction within the CT (Figure 7).

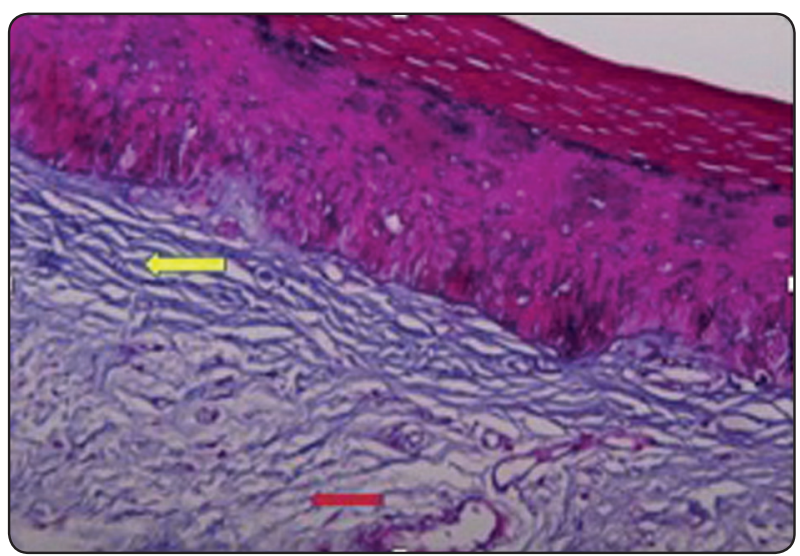

Fig. (4): A photomicrograph of hard palatal mucosa of Gp I, epithelium with well-formed keratin layer, CT showed almost equal amounts of mature collagen fibers (reddish in color, by red arrow) and immature fibers (bluish in color, by yellow arrow) normal-looking blood vessels (Masson Trichrome, Orig. Mg. x 200).

\section{b) Group II}

\section{Sub-group II.a (Senile Control)}

LM examination of this group specimens' epithelium showed some positive reactions alternating with negative ones in basal and parabasal cell layers. CT displayed apparently fewer positive cells (Figure 8).

\section{Sub-group II.b (Melatonin)}

LM examination of this groups' specimens showed that majority of basal and parabasal cells of the epithelium displayed strong positive reaction as well as numerous CT cells (Figure 9).

\section{Statistical Results}

Data were statistically described in terms of mean \pm standard deviation $( \pm$ SD). Comparison of numerical variables between the studied groups, was done using one-way analysis of variance (ANOVA) test with Post HOC multiple 2-group comparisons. P-values less than 0.05 was considered statistically significant. All statistical calculations were done using computer program SPSS (Statistical Package for the Social Science; SPSS 20.0, Inc., Chicago, IL, USA).

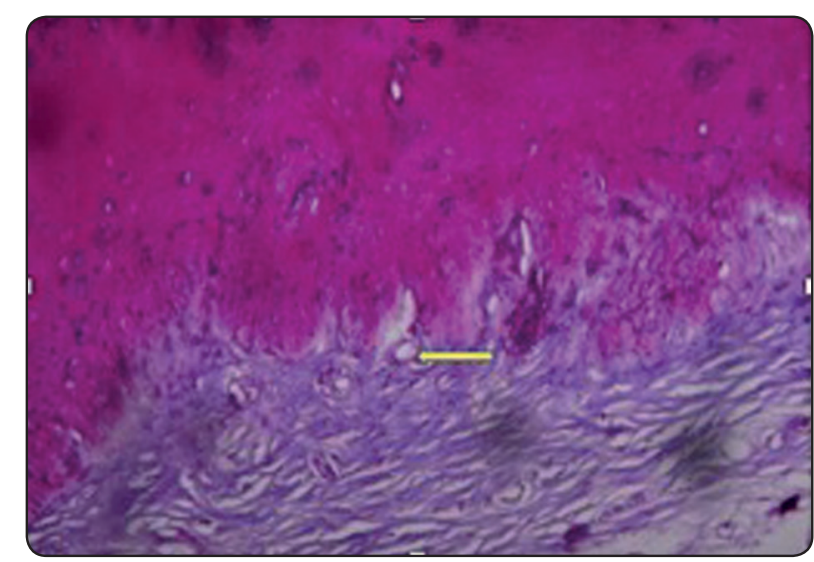

Fig. (5): A photomicrograph of hard palatal mucosa of (Gp IIa: senile) showing epithelium with numerous vacuolated cells. CT showed abundant mature (reddish) collagen fibers, few narrow blood vessels (arrow) (Masson Trichrome, Orig. Mg. x 200). 


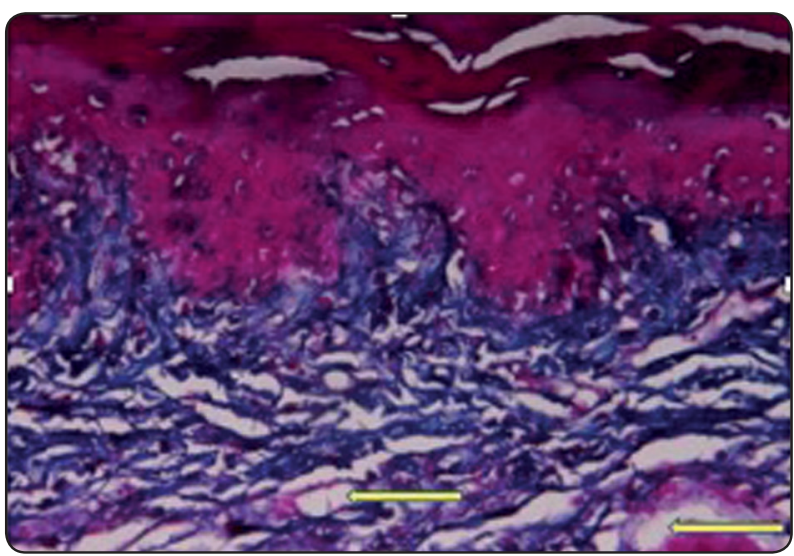

Fig. (6): A photomicrograph of hard palatal mucosa of (Gp IIb: Melatonin) showing normal epithelium. CT with intensely blue collagen fibers(immature), blood vessels of variable diameters (arrows), no extracellular edema was detected (Masson Trichrome, Orig. Mg. x 200).

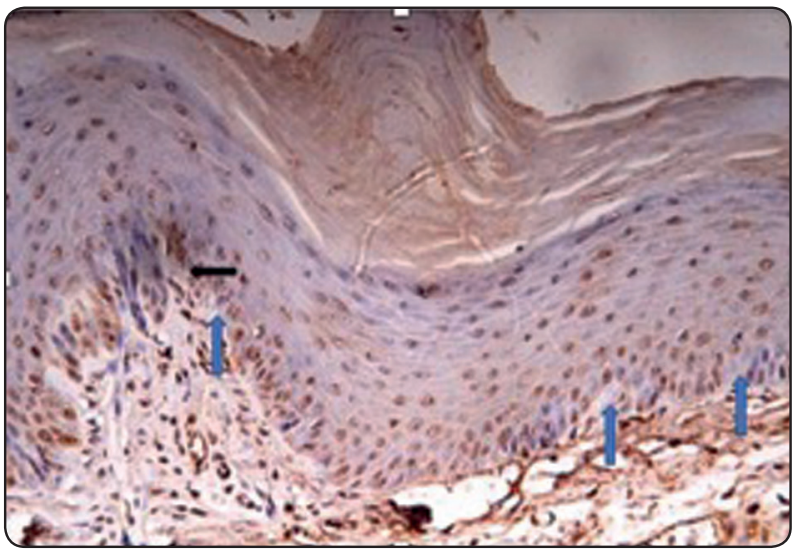

Fig. (8): A photomicrograph of hard palatal mucosa of (Gp IIa) showing some positive reactions (black arrow) alternating with negative ones (blue arrows) in basal and parabasal cell layers of the epithelium. CT displayed apparently fewer positive cells (Anti- PICNA, Orig. Mg. x200).

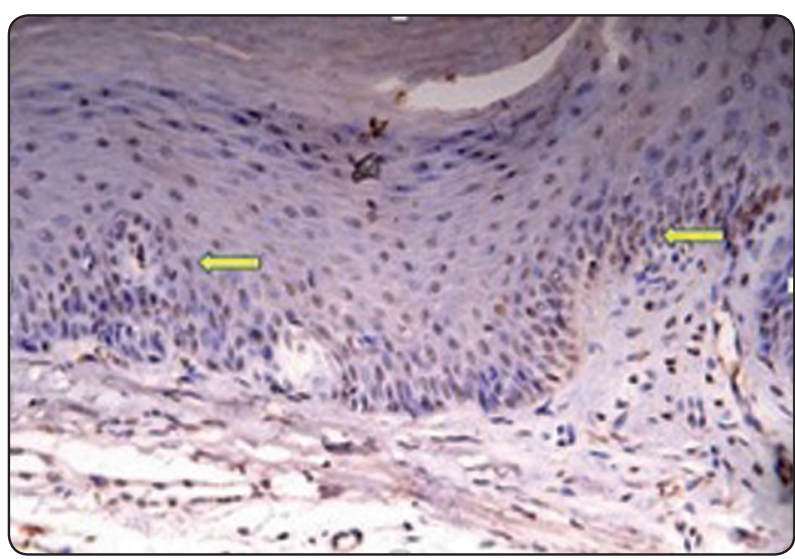

Fig. (7): A photomicrograph of hard palatal mucosa of (Gp I) showing distinct positive reaction in all basal and few para-basal cells of the epithelium(arrows), some cells with positive reaction within the CT (Anti- PICNA, Orig. Mg. x200).

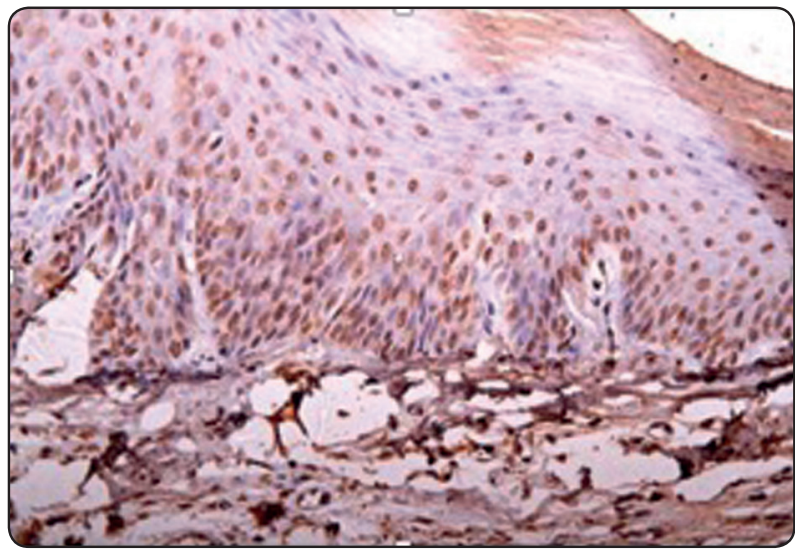

Fig. (9): A photomicrograph of hard palatal mucosa of (Gp II.b) showing strong positive reaction in almost all basal and parabasal cells of the epithelium as well as in CT (AntiPICNA, Orig. Mg. x200). 
The results of the present study are demonstrated in the following tables and figures.

Table (1): Comparison between groups according to their collagen content, regarding mature and immature fibers' percentage.

\begin{tabular}{|c|c|c|c|c|c|}
\hline Collagen & Group I (Young Control) & Group IIa (Senile Control) & Group IIb (Melatonin) & $\mathbf{F}$ & p-value \\
\hline \multicolumn{6}{|l|}{ Mature\% } \\
\hline Mean \pm SD & $0.100 \pm 0.173$ & $33.760 \pm 5.545 \mathbf{a}$ & $2.487 \pm 3.493 \mathbf{b}$ & \multirow{2}{*}{73.873} & \multirow{2}{*}{$<0.001 * *$} \\
\hline Range & $0-0.3$ & $27.87-38.88$ & $0-6.48$ & & \\
\hline \multicolumn{6}{|c|}{ Immature \% } \\
\hline Mean \pm SD & $29.337 \pm 5.520$ & $0.343 \pm 0.511 \mathrm{a}$ & $30.453 \pm 9.252 b$ & \multirow{2}{*}{22.545} & \multirow{2}{*}{$0.002 *$} \\
\hline Range & $26.11-35.71$ & $0-0.93$ & $20.18-38.13$ & & \\
\hline
\end{tabular}

F- One Way Analysis of Variance; Post HOC test LSD

a: significant difference with group I; $\boldsymbol{b}$ : significant difference with group IIa

p-value $>0.05 \mathrm{NS}$; *p-value $<0.05 \mathrm{~S}$; **p-value $<0.001 \mathrm{HS}$

This table shows statistically significant difference between tested groups according to their collagen content regarding mature and immature fibers percentage.

Table (2): Comparison between tested groups according to their epithelial thickness.

\begin{tabular}{|l|c|c|c|c|c|}
\hline Epith Thickness & $\begin{array}{c}\text { Group I (Young } \\
\text { Control) }\end{array}$ & $\begin{array}{c}\text { Group IIa (Senile } \\
\text { Control) }\end{array}$ & $\begin{array}{c}\text { Group IIb } \\
\text { (Melatonin) }\end{array}$ & F & p-value \\
\cline { 1 - 4 } Mean \pm SD & $374.46 \pm 191.60$ & $278.61 \pm 216.86$ & $415.76 \pm 184.62$ & \multirow{2}{*}{0.882} & 0.431 \\
\hline Range & $198.09-786$ & $81.61-690.42$ & $138-654.03$ & & 0.42 \\
\hline
\end{tabular}

F- One Way Analysis of Variance; p-value $>0.05$ NS

This table shows no statistically significant difference between tested groups according to their epithelial thickness.

TABLE (3): Comparison between groups according to their No. of vacuolated epithelial cells.

\begin{tabular}{|l|c|c|c|c|c|}
\hline $\begin{array}{l}\text { No. of Vacuolated } \\
\text { Epithelial Cells }\end{array}$ & $\begin{array}{c}\text { Group I (Young } \\
\text { Control) }\end{array}$ & $\begin{array}{c}\text { Group Iia } \\
\text { (Senile Control) }\end{array}$ & Group Iib (Melatonin) & F & p-value \\
\hline Mean \pm SD & $12.778 \pm 5.333$ & $53.222 \pm 14.342 \mathbf{a}$ & $12.889 \pm 5.819 \mathbf{b}$ & \multirow{2}{*}{54.782} & $<0.001^{* *}$ \\
\hline Range & $5-21$ & $34-79$ & $6-23$ & \\
\hline
\end{tabular}

F- One Way Analysis of Variance; **p-value $<0.001 \mathrm{HS}$

Post HOC test LSD: $\boldsymbol{a}$ : significant difference with group I; $\boldsymbol{b}$ : significant difference with group Iia

This table shows statistically significant difference between groups according to their no. of vacuolated epithelial cells. 
TABLE (4): Comparison between groups according to their No. of PCNA +ve cells.

\begin{tabular}{|l|c|c|c|c|c|}
\hline $\begin{array}{l}\text { No. of PCNA +ve } \\
\text { cells }\end{array}$ & $\begin{array}{c}\text { Group I (Young } \\
\text { Control) }\end{array}$ & $\begin{array}{c}\text { Group Iia (Senile } \\
\text { Control) }\end{array}$ & $\begin{array}{c}\text { Group Iib } \\
\text { (Melatonin) }\end{array}$ & F & p-value \\
\hline Mean \pm SD & $80.889 \pm 11.208$ & $31.000 \pm 16.325 \mathrm{a}$ & $91.333 \pm 12.490 \mathrm{~b}$ & 51.215 & $<0.001^{* *}$ \\
\hline Range & $65-98$ & $13-61$ & $69-110$ & \\
\hline
\end{tabular}

F- One Way Analysis of Variance; **p-value $<0.001$ HS

Post HOC test LSD: a: significant difference with group I; $\boldsymbol{b}$ : significant difference with group Iia

This table shows statistically significant difference between tested groups according to their no. of PCNA +ve cells.

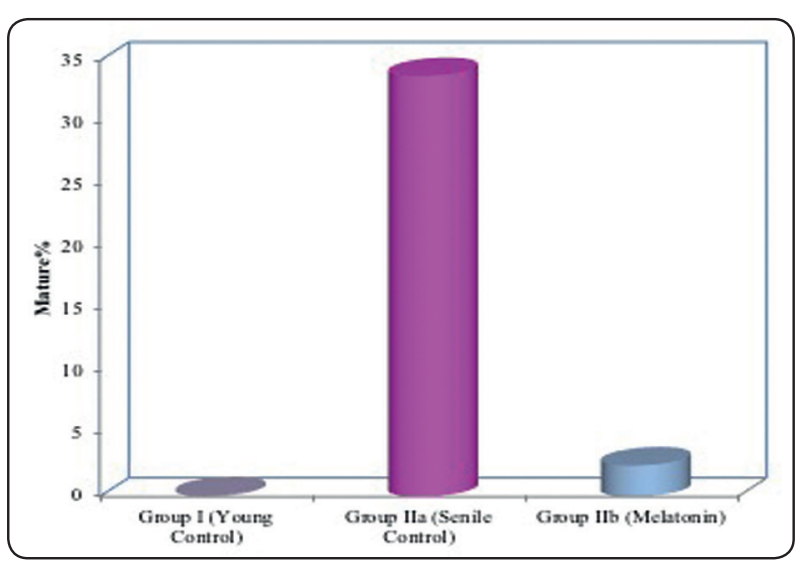

Fig. (10): Bar chart between groups according to their mature collagen fibers' percentage

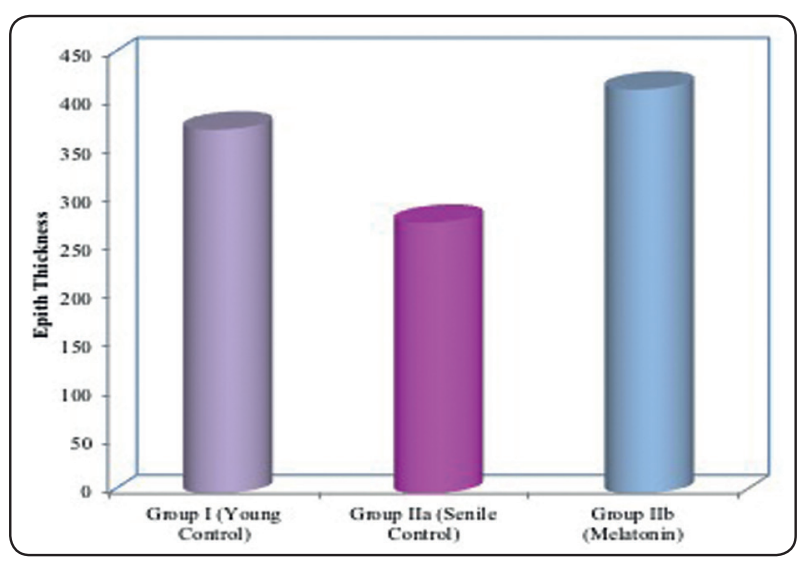

Fig. (12): Bar chart between groups according to their epithelial thickness.

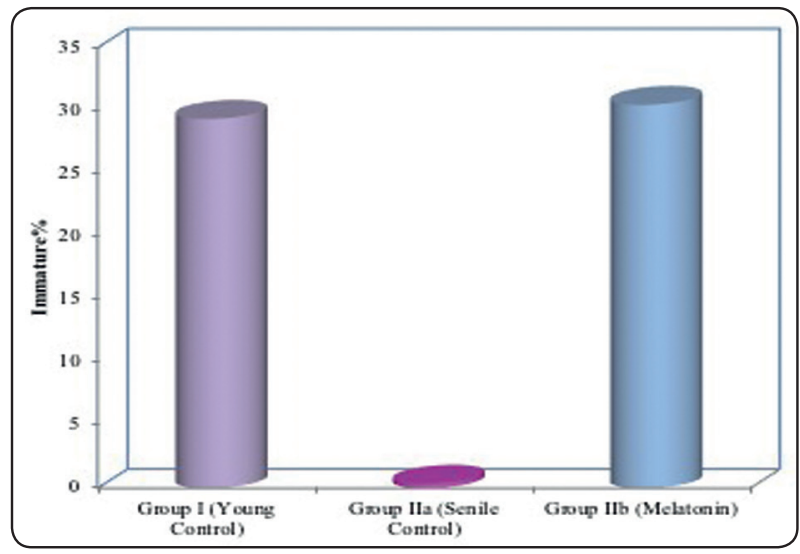

Fig. (11): Bar chart between groups according to their immature collagen fibers' percentage.

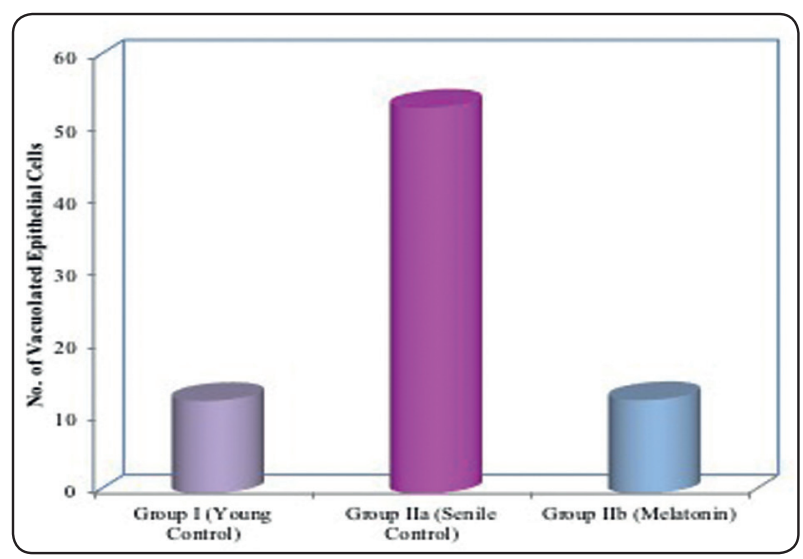

Fig. (13): Bar chart between groups according to their No. of vacuolated epithelial cells. 


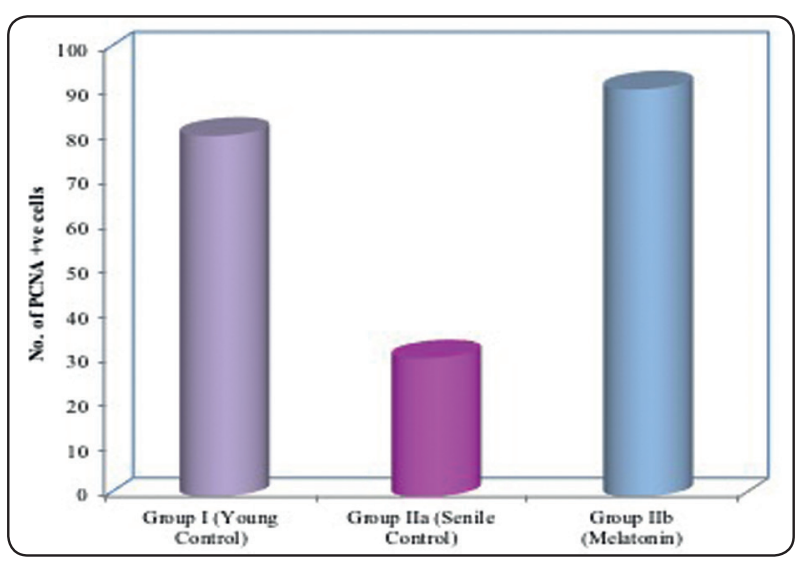

Fig. (14): Bar chart between tested groups according to their No. of PCNA +ve cells.

\section{SUMMARY OF STATISTICAL RESULTS}

- Group IIa (Senile), showed the significantly highest mean number of vacuolated epithelial cells within its epithelium, the highest area percentage of mature collagen fibers within its CT, and the least mean number of PCNApositive cells. However, the reduction in epithelial thickness of this Gp was nonsignificant, as compared to the other groups.

- Group IIb (Melatonin), showed the significantly lowest mean number of vacuolated epithelial cells within its epithelium, the highest area percentage of immature collagen fibers within its $\mathrm{CT}$, and the greatest mean number of PCNApositive cells. However, the increase in epithelial thickness of this Gp was non-significant, as compared to the other groups.

\section{DISCUSSION}

Aging is a harsh physiologic process changing various tissue components and deteriorating its structural integrity. In oral tissues, this structural agerelated changes predispose to various oral diseases if not properly managed. Meanwhile, the aging process reduces tissue ability for regeneration due to decreased cellular density and mitotic activity, and this must be carefully considered while choosing a line of treatment like an implant or denture or so ${ }^{[12]}$. Agwaral, et al ${ }^{[13]}$, stated that age-related oral diseases can cause xerostomia, generalized oral pain, difficulty in speaking, mastication, and swallowing, thus compromising the patient's quality of life.

In this study, the hard-palatal mucosa was chosen because in old age, due to loss of teeth in many instances, it is subjected to many forces, mainly frictional ones (as in full dentures), requiring intact mucosa to withstand various functional activities. Therefore, this study was designed to evaluate the extent of tissue protection offered by melatonin against age-related changes.

Light microscopic (LM) examination of Gp IIa (senile) specimens of the present study, revealed highly increased vacuolated epithelial cells within the epithelium, increased area percentage of mature collagen fibers within the $\mathrm{CT}$, and at the same time, reduced PCNA-positive cells, and epithelial thickness. The first three parameters were statistically confirmed.

These findings indicated enhanced apoptotic activity and reduced proliferative activity in epithelial cells, explaining the apparent thinning of epithelium of this Gp. Moreover, the increased amount of mature collagen fibers demonstrated by Masson Trichrome stain in the CT of this group's specimens, indicated diminished ability of fibroblasts to synthesize new collagen fibers with age. The CT of this Gp showed reduced cellularity and vascularity. Some CT areas displayed various degrees of hyalinization of collagen fibers, which was detected in some H\&E-stained specimens of this Gp. Other CT areas showed some inflammatory cell infiltration. These findings matched those of Revira, et al ${ }^{[12]}$, who found that aging resulted in reduction in epithelial ridges, epithelial atrophy, reduction of cellular density and mitotic activity. They also reported increase in fibrous elements of CT in relation to its cellular components. All of the previous findings in the current study, could be explained by 
the fact that ROS tends to accumulate within tissues with advancing age, due to diminished tissue ability to remove them. ROS results in tissue collagen destruction secondary to MMPs activation. Also, ROS is responsible for the inflammatory cell infiltration within the $\mathrm{CT}$ due to release of inflammatory cytokines ${ }^{[14]}$.

ROS and reactive nitrogen species (RNS) are reactive molecules that contain oxygen and nitrogen, respectively. They occur naturally within the tissues, but in trace amounts, and when their production increases, they're capable of causing harmful oxidative stress. Normal cells protect themselves from oxidative stress using both enzymatic and non-enzymatic antioxidants, with the former including superoxide dismutase (SOD), glutathione peroxidase (GPX), myeloperoxidase, and catalase and the latter vitamins, minerals, polyphenols and thiols ${ }^{[15]}$. Javed, et al ${ }^{[16]}$ stated that MMPs are enzymes that not only degrade collagens and extracellular matrix (ECM) proteins but can also regulate the activity of many bioactive molecules, like cell surface receptors and the release of apoptotic ligands. Thus, both ROS and MMPs interact together to cause tissue destruction.

LM examination of Gp IIb (Melatonin) revealed greatly enhanced proliferative activity of epithelial cells due to greatly increased PCNA-positive cells, which was confirmed statistically, as well as statistically significant reduction of vacuolated epithelial cells indicating lowered apoptotic activity. Moreover, this Gp's specimens displayed statistically significant increase in immature collagen fibers content within the CT (by Masson Trichrome staining), indicating improved regenerative ability of tissue fibroblasts. The epithelial thickness of this Gp's specimens apparently increased but was not statistically significant. The CT displayed enhanced cellularity and vascularity as well as diminished or even rarely detected inflammatory cells, ensuring the powerful anti-inflammatory action of melatonin which was reported by Cevik, et al ${ }^{[14]}$. The current study findings proved the anti-oxidant potential of melatonin, which was reported previously in many researches. These studies reported that melatonin modulated apoptotic proteins, hence reducing apoptosis ${ }^{[4]}$, improved vascular endothelial function ${ }^{[5]}$, resulted in efficient elimination of ROS and nitric oxide ${ }^{[6]}$, and provided protection against age-related mitochondrial dysfunction ${ }^{[7]}$. All of these miraculous effects of melatonin were welldisplayed in the current study, in the form of reduced apoptotic activity, enhanced cellular proliferation, enhanced vascularization, reduced inflammatory cells in CT, enhanced new collagen production, and diminished collagen destruction or hyalinization. Therefore, it is of vast importance to start antioxidant intake (as melatonin) at an early stage of the aging process to guard against development of age-related tissue changes.

\section{REFERENCES}

1. Moneim A, Librero A, Florido J, Shen Y, Fernandez B, Castroviejo D, et al. Oral Mucositis: Melatonin Gel an Effective New Treatment. Int J Mol Sci. 2017, v 18 (5);1003. Doi: 10.3390/ijms 18051003

2. Kamal M and Cicek M. Differential Immunohistochemical expression of Type I collagen and MMP2 among major salivary glands of young and geriatric mice. J Appl Oral Sci. 2018; 26 e 20170484.

3. Moayedi Y, Bianchi L and Lumpkin E. Somatosensory Innervation of the Oral Mucosa of Adult and Aging Mice. Sci Rep. 2018 Jul2; 8(1): 9975. Doi: 10.1038/s41598-01828195-2.

4. Amin A, El Missiri M and Othman A. Melatonin Ameliorates Metabolic Risk Factors, Modulates Apoptotic Proteins, and Protects the rat heart against diabetes-Induced Apoptosis. Eur J Pharmacol. 2015 Jan 15; 747: 166-73. Doi 10.1016/j.ejphar.2014.12.002.

5. Sartori C, Dessen P, Mathieu C, Monney A, Bloch J, Nicod P, et al. Melatonin Improves Glucose Homeostasis and Endothelial Vascular Function in High-Fat DietFed Insulin-Resistant Mice. Endocrinology. 2009 Dec; 150(12):5311-7. Doi: 10.1210/en.2009-0425. 
6. Ma P, Yan B, Zeng Q, Liu X, Jiao M, Wu Y, et al. Oral Exposure of Kunming Mice to Diisononyl Phthalate Induces Hepatic and Renal Tissue Injury Through the Accumulation of ROS. Protective Effect of Melatonin. Food and Chemical Toxicology. Vol 68, June 2014.pages 247-256. Doi:10.1016/j.fct.2014.03.027.

7. Sayed RKA, Fernandez M, Diaz M, Rusanova I, Rahim I, Escame G, et al. The Protective effect of Melatonin Against Age-Associated, Sarcopenia-Dependent Tubular Aggregate Formation, Lactate Depletion and Mitochondrial Changes. J Gerontol A Biol Sci Med Sci. 2018 Sep 11;73(10):1330-1338. Doi: 10.1093/Gerona/gly059.

8. Karaer C, Simsek G, Yidiz A, Vardi N, Polat A, Tanbek K, et al. Melatonin's Protective Effect on the Salivary Gland Against Ionized Radiation Damage in Rats. J Oral Pathol Med. 2016 Jul;45(6):444-9. Doi: 10.1111/jop.12386.

9. Sengupta P. The Laboratory Rat: Relating Its Age with Human's. Int J Prev Med. 2013 June; 4(6): 624-630. PMID: 239300179.

10. Bancroft $\mathbf{J}$ and Gamble M. Theory and Practice Of Histological Techniques. $6^{\text {th }}$ edition, 2008. Pages 146-150.
11. Mohsen R, Halawa A, Hassan R. Role of Bone MarrowDerived Stem Cells Versus Insulin on Filiform and Fungiform Papillae of Diabetic Albino Rats (Light, Fluorescent and Scanning Electron Microscopic Study). Acta Histochemica. 2019 (121) : 812-822.

12. Rivera. C. Gerodontology: Effects of Aging on the Oral Mucosa. Rev. Clin. Periodontica Implantol. Rehabl. Oral. Vol 10 no. 1, 2017. Doi: 10.4067/s0719-01072017000100009.

13. Agrawal B, Chandra A, Singh S and Agrawal S. Effect of Age on Oral Tissues. IJDSR. Vol 29(3). July 2011.

14. Cevik-Aras H, Ekstom J. Anti-inflammatory action of Cholecystokinin and Melatonin in the Rat Parotid Gland. Oral Dis. 2010 Oct; 16(7): 661-7. Doi: 10.1111/J.16010825.2010.01672.x.

15. Kesarwala A, Krishna M and Mitchell J. Oxidative Stress in Oral Diseases. Oral Dis. 2016 Jan, 22(1): 9-18. Doi: 10.1111/odi.12300.

16. Javed M, Hameed S. Recent Avances in Role of Matrix Metalloproteinases in Some Dental Diseases. Int J Dentistry Oral Sci. 2016, 3(10);344-347. Doi: 10.19070/2377-80751600070 